\title{
MEDIATISATION AND THE TRANSFORMATION OF \\ CAPITALISM: THE ELEPHANT IN THE ROOM
}

\section{Graham Murdock}

\begin{abstract}
Recent years have seen the idea of mediatisation promoted as a unifying concept capable of overcoming the increasing specialisation and fragmentation of communication research and addressing the increasing ubiquity and centrality of media across all areas of institutional and intimate life. Advocates present it as media centred but not media centric, arguing for inquiry that explores the interconnections between innovations in media and wider social and cultural change. While shifts in the organisation of economic activity are referenced, mediatisation research has not so far developed a comprehensive analysis of the central role played by the resurgence of market fundamentalist models of capitalism in reorganising the relations between media and social and cultural life it seeks to address. Through a close reading of key writings on mediatisation, this article demonstrates the necessity of integrating a critical political economy into its core project.
\end{abstract}

KEYWORDS mediatisation; critical political economy; market fundamentalism; capitalist modernity

\section{Introduction}

Onevariant of the popular parable recounts howagroup of men, stumbling across an elephant in a pitch-dark room and unable to see the animal, set out to build a picture of its overall shape by exploring its body. Each feels a different part and comes to a different conclusion. After a period of argument they agree to pool their impressions in the hope of producing a more complete account.

Media and communications inquiry has followed a similar path with the field splintering into an ever-expanding range of specialisms. Faced with the ubiquity of digital media and their accelerating integration into intimate and institutional life at every level, from the presentation of the self to the organisation of state surveillance and military strikes, this fragmentation of attention and effort has appeared less and less adequate for understanding the role media now play in contemporary societies. The growing sense that "something is going on with media in our lives, and it is deep enough not to be reached simply by accumulating more and more specific studies" (Couldry and Hepp 2013, 191), has prompted a search for a new integrative framework and, after the usual battles over labels, mediatisation has emerged as the favoured approach to detailing the range of "transformations in the nature of contemporary social order linked to the affordances and uses of media" (Couldry 2014, 38).

An integrative perspective requires a strong commitment to connecting analysis conducted at differentlevels and exploring theinterplay betweensituated action and structural (C) 2017 EURICOM 
conditions. Stig Hjarvard (2011, 121), one of mediatisation theory's main proponents, claims that unpacking "the interactionand transaction between actors and structures" is one of the project's central ambitions. His own research, however, has tended to operate at the level of institutional change, employing a variant of Anthony Giddens' structuration theory to explore how media processes have become increasingly "integrated in the operations of other social institutions and cultural spheres" (Hjarvard 2013,17) pressuring them to adapt to and work with the "logic" embedded in the "various operational modalities by which media enable, limit and structure human communication and action" (Hjarvard 2011, 123; original emphasis). Despite the reference to structures as enabling as well as constraining, advocates of the other main current of mediatisation research-which focuses on transformations in everyday life and draws on social constructionist perspectives-see the notion of inherent media "logics" as overly directive and leaving too little room for the diversity and creativity of situated agency. As Andreas Hepp has argued, "The conception of mediatization as the propagation of a 'media logic' involves a reification, placing the process beyond human agency" and presenting it as "something that 'happen' all by itself ... not something that we ourselves create" (Hepp 2016, 927). He describes his own work as a concerted attemptto "open the 'black box' of media related logic(s) and introduce a more empirically grounded actor perspective into our analysis" $(2016,920)$.

In hisfoundational essay, Winfried Schulz $(2004,90)$ argues that the core meaning of mediatisation lies with the ways that the technological, semiotic and economic characteristics of various media became increasingly central to both personal and institutional practices. Subsequent work has paid sustained attention to media as arrays of technologies and systems of representation. Schulz emphasises how, "as media use becomes an integral part of private and social life, the media's definition of reality amalgamates with the social definition of reality", reshaping everyday understandings of the world $(2004,89)$. Other writers have focused on the processes "through which media technologies and related artefacts become indispensable to people in the everyday lives" (Jansson 2014, 273). In contrast, mediatisation theorists have mostly ignored the third dimension of Schulz's model: the "economic".

Economic shifts and dynamics are mentioned but there has been no systematic attempt to explore the intersections between the increasing integration of media into social and cultural life and the transformation of modern capitalism from welfare to market fundamentalist models. In some ways this is a surprising omission because writers on mediatisation are at pains to stress that while their particular expertise lies with unpacking the "transformative potential" of media, they see this as contributing to a "holistic understanding of the various intersecting forces atwork" in reshaping contemporary societies (Hepp, Hjarvard, and Lundby 2015, 316). This emphasis on transformation necessarily defines mediatisation as a process unfolding over time, and despite their differences researchers in the fieldare united in "interpolating media analysisinto thelargerstory of modernity" (Lunt and Livingstone 2015,5 ). The problems begin with the conception of modernity underpinning this ambition.

\section{Modernity and Capitalism}

Some writers see mediatisation, understood as the progressive temporal, spatial and social spread of mediated communication (Krotz 2009), as a "process that has more or less 
been accompanying the whole history of mankind" (Hepp and Krotz 2014, 10). Others date the increasing "social and cultural relevance" of media from the "emergence of so-called 'independent' mass media" (Hepp and Krotz 2014, 10). The majority of commentators, however, follow Hjarvard $(2013,18)$ in seeing mediatisation as a distinctive feature of the "late" or "high" modernity that crystallised in the second half of the twentieth century. For Winfried Schulz, the decisive moment comes with television's installation as a ubiquitous and central presence in domestic life, prompting him to suggest that it "would be more appropriate to use the label 'televisualisation' for recent socio-political changes" rather than mediatisation (Schulz 2004, 94). The subsequent emergence of the Internet as a mass utility and the migration of access from laptops to mobile devices have led recent writers to nominate smartphones and tablets as the new pivots of mediatised modernity.

These accounts are grounded in a model of modernity that presents it as the product of a series of interlinked but separate transformative meta-processes which enjoy more or less equal analytical status and explanatory purchase. Alongside mediatisation the list typically includes urbanisation, globalisation and individualisation (see, for example, Krotz 2007; Hjarvard 2011, 120). This model pointedly ignores the primacy of capitalist dynamics in shaping the central contours of modernity.

While the major cities and empires of the ancient and mediaeval worlds point to significant histories of urbanisation and globalisation that pre-date the rise of modern capitalism, their contemporary forms have been fundamentally moulded by capitalist dynamics. The leading urban centres of the contemporary world have been constructed around industrial, financial, trading, export and administrative hubs that service capital. Present patterns of globalisation have been indelibly marked by capitalist colonisations and imperialisms and their legacies. Under the relentless drive to maintain models of growth predicated on ever-increasing levels of personal consumption, conceptions of individuality have been progressively annexed by capitalism's core ideology of possessive individualism.

Writers on mediatisation often include economic dynamics in their inventories of contemporary transformative processes under the heading of "commercialisation", but shifts in the organisation of the media system since the mid-1970s are never located within a more comprehensive account of the wider transformation of capitalism and its multiple implications for the organisation of economic and symbolic power. This absence appears like a ghost haunting recent commentaries by leading writers on mediatisation. In their efforts to compile a more complete account of the elephant they have neglected to ask who owns and trains it and what it is doing in the room.

As Andreas Hepp and Friedrich Krotz acknowledge, "a critical analysis of the interrelation between the change of media and communication, on the one hand, and the change of culture and society on the other" (Hepp and Krotz 2014, 7) cannot take "media unquestioned as the source of change" and must give serious consideration to the possibility that "the driving force of change might not be the media at all" $(2014,10)$. In an earlier commentary, Krotz goes one step further, arguing that although the relations between the core dynamics of modernity are complex with each having its own logic of development, "in a capitalistic world all such meta-processes depend on the economic dimension" and "thus commercialisation is the basic process providing the stimulus to all action" (Krotz 2007, 259). If this is the case then accounts of mediatisation, whether focused on the shifting organisation of institutional relations or the changing textures of every life and interaction, must necessarily engage fully with the transformation of 
contemporary capitalism and its consequences for the organisation of media and communications. Major economic shifts have forced their way into accounts of mediatisation but have been quickly passed over. The growing concentration of ownership over key communications facilities is a case in point. In a recent paper, Andreas Hepp and colleagues concede that "we might explain ... the concentration of media organisations and ownership ... by certain economic driving forces" (Hepp, Hjarvard, and Lundby 2015, 320) but they do not go on to relate these "driving forces" to the wider transformations generated by capitalism's turn to marketisation.

As Wolfgang Streeck has argued, "capitalism denotes both an economy and a society, and studying it requires a conceptual framework that does not separate the one from the other" $(2016,201)$. However, as he goes on to stress, "calling a society capitalist also implies that it is 'a society continually' at risk of the social relations governing the economy penetrating into and taking possession of previously non-capitalist social relations" $(2016,202)$. The period since the mid-1970s has seen precisely this process gather increasing momentum within the mature capitalist societies of the West, with far-reaching consequences for the organisation of communication systems and their role in the process of accumulation.

\section{From Mediatisation to Marketisation}

In the mid-1970s advanced capitalist economies experienced a severe structural crisis of profitability which opened the way for neo-liberal critiques of state intervention and management to gain increasing traction. The resulting ideological and practical promotion of private enterprise and markets was pursued with particular vigour and force in the major strongholds of the Anglo-American variant of capitalism, Great Britain and the United States, under the direction of Margaret Thatcher and Ronald Reagan, but elements of this marketised response to crisis also gathered increasing momentum within the European Union. The result was a fundamental rebalancing of the relations between states and markets that had characterised the post-war welfare model of capitalism constructed around strong regulation of private enterprise, a redistributive tax system and significant public investment in the core material and cultural resources required for full citizenship. Its displacement by a marketised model has been the defining force reshaping the contemporary communication system addressed in the mediatisation literature.

The pursuit of market fundamentalist responses to the crisis of profitability has had three major impacts on the organisation of media.

Firstly, and most obviously, these responses have very significantly increased the control that private corporations exercise over both the essential infrastructural supports for networked communication and the organisation, production and public circulation of information and cultural expression. Telecommunications systems that were previously public utilities or strongly regulated monopolies have been privatised and moved into the market sector. There has been no restriction on Google and Facebook building their own proprietarynetworks. The dilution or suspension of limits on media ownershiphas concentrated content production and distribution in the hands of a diminishing number of mega conglomerates, while the absence of effective regulation of corporate concentration on the Internet, coupled with network effects that favour dominant players, has ceded control over core uses to effective monopolies or duopolies. 
As a mounting number of studies have demonstrated, over the last three decades control over the global production and distribution of news and entertainment has become progressively concentrated in the hands of a steadily shrinking number of major communications conglomerates with interests across the whole range of print and audio visual media (see Bagdikian 2004; Birkinbine, Gomez, and Wasko 2017). This pattern has been repeated in intensified form in digital media, with the core areas of popular Internet use commanded by one or two dominant players: Google in search; Facebook in social media; Amazon in online retailing; and Apple and Microsoft in personal computing. These companies are not simply central to the contemporary communications system; they are at the heart of the emerging general economy of advanced capitalism.

Figures for 2016 show Apple, Alphabet (Google's holding company) and Microsoft occupying the top three places in the list of world's largest companies by market capitalisation, with Amazon in sixth place and Facebook seventh (The Economist 2016, 5). The dynamics propelling this seismic shiftin economic and symbolic power are not investigated in detail in the mediatisation literature.

Alongside this unprecedented consolidation of corporate control, public marketisation polices have eroded the power and autonomy of cultural institutions that previously provided counterbalances to the commercial annexation of public culture. Their funding from taxation has been progressively squeezed and they have come under increasing pressure to become more commercially minded. Museums find themselves unable to mount major exhibitions without significant corporate sponsorship. Public service broadcasters are continually urged to maximise the monetary value of their assets by aggressively selling programming and formats in overseas markets and exploiting the merchandising potential of popular shows.

The commercialisation of cultural production has been matched by the redirection of audience attention and use. One of the constituentcauses of the mid-1970s crisis profitability was the exhaustion of the mass production system that had sustained rising growth in the post-war period. The corporate response was four-fold (see Murdock 2014). Firstly, product standardisation gave way to differentiation and the increasing segmentation of markets by taste niches. Secondly, the obsolescence cycle was accelerated so that artefacts and styles became unfashionable at an increasing rate and had to be replaced. This new disposability was reinforced by the short shelf-life of spare parts and the disappearance of local repair facilities. Thirdly, the basis of product promotion shifted from price and utility to evocations of the centrality of commodities to lifestyles and personal identities. Fourthly, the stagnant or falling levels of household spending power resulting from the corporate suppression of wages and attacks on the collective bargaining power of trade unions were compensated for by a massive extension of personal borrowing on credit and store cards.

The rapid roll-out of new commercial media since the mid-1970s, with the introduction of cable and satellite channels and later the Internet, provided the primary support for this new consumer regime, both quantitatively, by massively expanding the space available to advertising, and qualitatively, by facilitating new integrated, interactive and immersive forms of product promotion. The impacts, however, have been uneven. The business model of the major Internet sites, based on harvesting and analysing users' personal data to develop more finely targeted and personalised marketing strategies, has proved remarkably successful and, as we noted earlier, positioned Google and Facebook among the world's leading corporations. At the same time, their rise has placed established media 
sectors that rely on advertising revenues under increasing financial pressure, intensifying their search for audience maximisation.

Looking across the range of current writing on mediatisation, however, we find that these impacts of marketised capitalism are either not mentioned or appear only in passing and are never fully engaged with.

\section{From Media Logics to Corporate Logics}

The institutional variant of mediatisation theory is based on claims that late modernity in democratic societies has seen a double movement whereby "media acquire the status of social institutions in their own right" but are, at the same time, increasingly "integrated into the operations of other social institutions and cultural spheres" (Hjarvard 2013, 17) which then become "to some extent dependent on the logic of the media" (Hjarvard 2011, 119)

This argument borrows from Altheide and Snow's influential conception which identifies media logic with the presentational formats employed by various media to structure "how material is organised, the style in which it is presented, the focus or emphasis on particular characteristics of behaviour" and argues that format provides the central "framework orperspective that is used to presentas well as interpretphenomenon" (Altheide and Snow $1979,10)$. Any individual or agency seeking to secure favourable publicity and mobilise public support is necessarily engaged in a three-way struggle: for voice and visibility; for legitimacy; and for precedence. It is a struggle to control the terms on which they are seen and heard and, where necessary, to suppress the circulation of negative imagery and damaging information. It is a struggle to be taken seriously. It is a struggle to install one's views or persona as the accepted point of reference against which all other alternatives and challenges are judged. Under conditions of capitalist modernity, mass media have become the major arenas in which these struggles are fought out.

As Stig Hjarvard, the main mediatisation theoristworking with the idea of medialogic, is careful to point out, however, "By the term ... we do not imply a singular, uniform logic that resides behind everylevel of media activity" and analysis "must take the specific features of the media in question into account" (Hjarvard 2011, 123). Different media formats and genres provide different spaces of expression and different mechanisms of exclusion. News relies predominantly on official sources and is therefore relatively "closed" as a cultural form, whereas fictional genres may offer more openness to the exploration of alternative and oppositional discourses and viewpoints (see Schlesinger, Murdock, and Elliott 1983).

Writing on mediatisation, however, has tended to follow the central tendency in political communications research more generally and focus primarily on the interplay between the organisation of news and the communication strategies of politicians and political parties. The core assertion is simple. As the media have become increasingly central to cultural life, so "politiciansand political institution have becomeincreasingly dependent" on them to command public attention (Strömbäckand Van Aelst2013,342) and in the process have moved from adapting to media logics to adopting them so that "standards of newsworthiness become a built in part of the governing process" (Strömbäck 2008, 239-240). The political logics and skills that previously determined communicative strategies are replaced by media logics that dictate the staging of events and the timing and form of announcements. 
Powerful empirical support for this argument is provided by Daniel Hallin's $(1992,5)$ demonstration that in the two decades between 1968 and 1988 the average length of quotations from candidates in Presidential elections on US network newscasts shrunk from 40 seconds to 10 seconds. He sees this movement towards greater compression as driven by two intersecting shifts. In the political sphere, the erosion of traditional party loyalties placed a greater emphasis on using the techniques of marketing and advertising to "sell" positions and policies in an increasingly competitive political marketplace. In the media sphere, increased competition from the rise of cable television put the established broadcast networks under increasing pressure to maintain ratings, prompting them to adopt a more entertainment-orientated approach to coverage. The result, Hallin argues, is to present electoral competition as a horse race, with peaks and spills, and to emphasise the personalities of candidates rather than the underlying issues addressed in competing policy platforms. As Donald's Trump's 2016 Presidential campaign illustrates, this process has intensified since Hallin's study.

There is now general agreement that Trump typifies the recent turn to populist politics across a number of western democracies. Ideologically his campaign drew on the classic populist opposition between a put-upon "people" and an out-of-touch establishment that had denigrated their core values and undermined their living standards. His career as a successful businessman with no political experience allowed him to presenthimself as an "outsider", unconnected to the dominant policy elites and absolved from blame for their failures, and as someone with a proven ability to get things done. Dismissing the claims of experts as unreliable and driven by special interests, he celebrated gut instinct and the wisdom of "common sense" grounded in lived experience.

In orchestrating these ideological appeals, Trump drew on what Moffit and Tormey see as populism's defining political style, deliberately disregarding “'appropriate' ways of acting in the political realm", resorting to calculatedly disruptive behaviour and displaying a "heady combination of charisma [and] political incorrectness" (Moffitt and Tormey 2014, 392 and 393). His performances drewon his experience and persona as the host of thelongrunning US version of the game show The Apprentice, designed to select managers for his portfolio of companies. He became famous for his acerbic and dismissive comments on unsuccessful contestants, and the show's catch-phrase "You're fired" perfectly encapsulated his central campaign promise to purge Washington of the experts and bureaucrats he claimed had failed "the people".

Writers working within a mediatisation perspective would be inclined to follow Jesper Strömbäck in arguing that these findings confirm the installation at the heart of contemporary public culture of a "media logic" promoting "news values and storytelling techniques" organised around "simplification, polarization, intensification, personalisation" (Strömbäck 2008, 233). Far from complying with the requirements of standard media formats, however, throughout his campaign Trump adopted an adversarial stance towards the mainstream news media, including them on his list of "liberal" establishment institutions driven by self-interested agendas. He chose instead to communicate directly with supporters, speaking at a continuous series of rallies across the country and using his Twitter account on a daily basis to float policy proposals, comment on opponents and issue rebuttals to criticisms. These performances set the media agenda.

Confronted with a campaign that was light on sustained discussion of key issues and organised around Trump's personality and provocative statements, the US broadcast networks had two choices. They could provide considered analysis of the core issues facing 
the country or they could collude with Trump's orchestration of his campaign. As Nicholas Kristof has pointed out, they chose "complicity since such tactics were easy to shoehorn into ratings pleasing entertainment structures" and "everyone knew that Trump was ratings gold, where a segment on poverty was ratings mud" (Kristof 2016). This conclusion is supported by research showing that whereas in 2008 (the last year included in Hallin's study) the broadcast networks devoted 220 minutes of air time to independent coverage of election issues, excluding those arising from candidates' statements or debates, in 2016 that figure had dropped to 36 minutes.

As Silvio Waisbord has noted, in its strongest form the argument from media logics presents them as an "inescapable" set of "expectations determined and embedded by the media" which "any institution or individual that 'goes public' need to meet" and comply with (Waisbord 2013, 183). The Trump campaign, however, offers a counter case that supports Nick Couldry's argument; that far from being "fixed necessities", media logics are "open to resistance and challenge, as well as complex variations and unevenness" (Couldry2014, 38).

Stromback $(2008,241)$ concedes that the increasing tabloidisation of political coverage has been largely driven by market forces, and goes on to argue that "a strong public broadcasting system can help to create a counterweight towards the commercialization" which may slow or even reverse the process of mediatisation $(2008,242)$. Historically, public service broadcasting's lack of dependence on advertising finance and its historic mission to educate and inform as well as entertain has indeed provided, at last potentially, a bulwark against the tabloidisation of programming and space for the interrogation of serious issues and minority positions. As we noted earlier, however, marketisation policies have whittled this space away by cutting public funding and pressuring public broadcasters to behave as though they were private companies, with the result that programming is increasingly pulled onto the terrain mapped out by the dominant commercial players. Opposing this requires an analysis of the full impact of commercialised cultural production coupled with a principled defence of the central role of public funding in providing essential alternative cultural resources for full and equal citizenship. The argument from media logics addresses consequences not causes.

A full analysis of the play of corporate power within the communications system is also curtailed by the other core claim of the institutional variant of mediatisation theory; that "the media have become increasingly independent from politics" (Strömbäck and Van Aelst 2013, 342). The definition of "independent" at work here takes the historic shift in the organisation of the newspaper press as paradigmatic. As Stig Hjarvard notes: "whereas in the first part of the twentieth century the political press served in many countries as a mouthpiece for particular political interests, parties, and movements", newspapers today "are primarily businesses governed by professional media considerations ... technological affordances and market demands" (Hjarvard 2011, 122). The political influence of press owners is conspicuously missing from this formulation.

The career of Rupert Murdoch and News International offers an instructive case study (see Murdock 2017). The fact that Murdoch has endorsed whichever candidate for prime minister or president is most likely to advance his business interests in the countries he operates in, famously switching support from Margaret Thatcher's Conservatives to Tony Blair's New Labour in Britain, could be interpreted as demonstrating his independence from party politics. But the category of politics is not exhausted by electoral competition. Cementing the terms of political debate over the long term is arguably more significant, 
and there is substantial evidence that Murdoch has consistently deployed his news interests in Britain, Australia and the United States to vigorously promote neo-liberal perspectives and polices and to denigrate and pillory positions he opposes. Murdoch's career also demonstrates another dimension of the connections between media and politics.

As Gianpietro Mazzoleni and Winfried Schulz point out in their formative discussion of mediatisation and democracy, "much 'politics of substance' is practiced away from media spotlights, behind the scenes, in the discrete rooms of parliament and government" (Mazzoleni and Schulz 1999, 250). Successive investigations have revealed the energy Murdoch has devoted to cultivating political connections, his privileged personal access to ministers and his ability to turn this social capital to commercial advantage in avoiding public scrutiny of key media acquisitions.

Characterising media as increasingly independent of party politics misses these wider articulations to the exercise of communicative power and influence in the political arena.

\section{From Representations to Infrastructures}

There is, however, another, more general problem with mediatisation theory's tendency to identify the political domain with party politics and to focus on the organisation of media representations. There is no systematic analysis of the central role played by communication infrastructures in organising fundamental state activities. Even the most militant advocates of marketisation concede that continued public funding is required to finance the military and intelligence capabilities needed to discharge the state's core functions of guaranteeing internal and external security. Both these functions have become progressively dependent on media systems but accounts of mediatisation miss crucial dimensions of these relations.

Sara Maltby's work on the mediatisation of the military, for example, chooses tofocus exclusively on the media management strategies devised within the military to "appeal to, reassure, and elicit support from multiple audiences" including state agencies and military personnel (Maltby 2012, 255). In a media-saturated culture, struggles over media representations and accounts are clearly central to any effort to secure funding and legitimacy but they do not exhaust the articulations between the organisation of the military and the organisation of communications. One of the defining characteristics of capitalist modernity has been the increasing resort to remote means of delivering armed force, fromaerial bombardment to missile attacks, drone strikes and robotic assault troops, coupled with their increasing reliance on command, control and communication networks capable of coordinating and directing complex operations with a high degree of accuracy. This key development in the organisation of modern armed conflict has generated a substantial literature across the social sciences but has not so far been incorporated into mediatisation theory's accounts of the increasing integration of media into institutional operations and strategies.

A similar lacuna surrounds the transformation of intelligence. Since the First World War, the interception and decoding of communications traffic has assumed an increasingly central role in state surveillance of people and organisation judged to pose a threat to internal or external security. As Andrew Gamble (1994) noted towards the beginning of the neo-liberal era, the extension of "free" markets in the economic sphere has been accompanied by the consolidation of a "strong state" in the domains of policing and 
intelligence. The rise of Islamic jihadism, the demonstrations of its destructive potential in the 9/11 attacks on New York and Washington and the London underground bombings, and its assumed organisational shift from centralised to networked and freelance operations have combined to move the monitoring of communications to the centre of intelligence gathering, licensing a shift from selective to saturation coverage in which everyday uses of the commercial Internet are routinely added to the stores of data collected by the security services for analysis and classification. Far from the media system becoming increasingly independent of the exercise of politics and political power, the consolidation of the strong state requires its increasing incorporation. There is an extensive body of research on this emerging regime of networked surveillance, but again the crucial challenges it poses for the exercise of citizens' rights and democratic politics have so far been left largely unexplored by proponents of marketisation theory

\section{Situated Action and Commercial Colonisation}

A failure to engage fully with the dynamics of marketised capitalism also characterises work on mediatisation that emphasises everyday agency rather than institutional logics.

Andreas Hepp and Friedrich Krotz recently proposed that research should focus on "the level where mediatization becomes concrete, where people use mediain specificcontexts with specific interests and intentions" (Hepp and Krotz 2014,14). One of the contexts they mention, where everyday activity is shaped in crucial ways by access to digital networks, is the stock exchange. Since the pioneering "Big Bang" in London in 1986 which replaced face-to-face interaction on the exchange floor with computerised screen-based dealing, financial transactions around the world have increasingly centred around global communications networks and algorithms that respond automatically to movements in prices, buying and selling at pre-set levels. The social enclaves based around these communicative hubs clearly fit Heppand Krotz's conception of situated "mediatized worlds". At the same time, the micro world of financial dealing is nested within a wider set of transformations in contemporary capitalism consequent upon the central role that financial institutions have come to play in orchestrating economic life. This financialisation of capitalism is both a meta-process of change and an essential framing context for situated economic action. A full analysis needs to move between and link these levels, as Karen Ho does in her path-breaking ethnography of Wall Street investment banks (Ho 2009) which sets out to "situate global capitalism" by demonstrating how its core structures are maintained through a repertoire of everyday performances (Ho 2005). In the light of the 2008 financial crash we now need to add an account of how these performances, in turn, generated a structural crisis. Exploring the ways communication systems are deployed is a necessary but not a sufficient condition for a full analysis (see Murdock 2015).

Turning to popular use of digital networks finds mediatisation theorists continuing to emphasise the Internet's democratising and equalising potential. Nick Couldry, for example, has drawn attention to the expanded opportunities it offers people to "tell important stories about oneself- to represent oneself as a social, and therefore potentially political, agent-in a way registered in the public domain" (Couldry 2008, 386). The major contemporary social media platform for these narratives is Facebook; Couldry notes this but does not engage with the point made by Andreas Hepp and colleagues that analysis needs to explore the "commodification of social relationships due to the commercial dynamics embedded in 
Facebook" (Hepp, Hjarvard, and Lundby 2015, 317). There is a now a substantial literature on the way Facebook "monetises" the free labour of the site's users and employs algorithms based on their past preferences to organise the material that appears on their personal page (see Bucher 2012; Fuchs 2013). This does not negate the value of exploring the ways individuals employ Facebook and other social media platforms as sites of self-expression and exploration and social connection, but it does underline the need, as Couldry (2008, 375) himself emphasises, to interrogate the "heterogeneity of the transformations to which media give rise across complex and divided social space". This space is defined by the tensions between personal projects, social mobilisations and corporate strategies and logics, and it is precisely the relations between them that analysis needs to focus on.

Hepp's own recent work has explored the social mobilisations set in motion by three groups of activists in the vanguard of developing new applications of digital technologies; the "maker" movement, the open data movement and enthusiasts of the quantified self. He presents them as pioneering communities "who understand media technology as a key instrument in facilitating 'new' and 'better' forms of collectivity" (Hepp 2016, 927). Closer investigation, however, reveals strong links to commercial players intent on promoting corporate rather than public interests. Personal devices designed to monitor health and fitness are central to the promotion of an ideal of the quantified self that valorises individual responses to warning signs of, for example, weight gain or infection. The result is a boost for the pharmaceutical industry rather than public health care.

In his presentation of the "maker" movement, Heppquotes, approvingly, the vision of the "next Industrial Revolution" promoted by Chris Anderson(2012), the editor of Wired, the house magazine of the Silicon Valley digital corporations. This envisages computerised design and 3-D printers "paving the way for ... product development ... carried out by collectives using media whose designs are then realised in robotised factories" (as quoted in Hepp 2016, 928). Hepp, like Anderson, presents this as a democratising movement, decentralising production. This rosy vision fails to explore why this coming "industrial revolution" is more likely to consolidate corporate control. Dominant uses of new "inventions" will be directed forcefully by the vigorous application of intellectual property law and promoted by the full armoury of corporate advertising and marketing. The increasing use of robotised production will generate substantial job losses, further reinforcing income and wealth inequalities and their attendant exclusion of the poor from full social inclusion. The routine installation of artificial intelligence in finished products will massively expand the range of "smart machines" integrated into the "internet of things" collecting and transmitting data on consumer preferences, personal habits and everyday activities on behalf of corporations but without the volition or control of users.

Samsung's new "smart" television sets, for example, automatically log the everyday conversations taking place in front of screen and make them available to interested corporations.

The advent of the Internet of things forcibly reminds us that media are also assemblies of physical infrastructures and machines which are manufactured under certain conditions, consume scarce resources in their design, production and use, and pose problems of waste and pollution in their disposal. As the editors of a recent collection on media technologies note, "in communication and media scholarship ... the materiality of devices and networks has been consistently overlooked" (Gillespie, Bockzkowski, and Foot 2014, 1). Work on mediatisation reproduces these absences. 
As noted by a leading contributor to what we can now begin to call the "material turn" in communication studies, "materiality is a complex multidimensional idea, and open to a variety of interpretations" (Lievrouw 2014, 25). I am using the term here in two senses: to highlight the need to investigate the raw materials and natural resources that are used up in producing and operating media machines and networks, and to return to the labour processes that transform these materials into commodities and networks. Recognising these materialities raises urgent questions about the relations between innovations in communication, the global circuits of capitalism and the gathering climate crisis.

Smartphones and cloud computing point to these intersections with particular force and clarity. The work of Qiu (2014), Fuchs (2014) and others has highlighted the exploitative labour conditions that are hidden from view by the wall of glamorous images promoting the desirability of the finished products and celebrating their indispensability to the ways we live and wish to live. Maxwell and Miller (2012) have forced us to confront the full environmental consequences of present modes of producing, using and disposing of media machines and maintaining communication networks.

The extensive and very concrete server farms concealed behind the metaphor of the immaterial cloud require huge amounts of energy to run and use massive volumes of water forcooling. The political decision to assign priority to these requirements has majorimpacts elsewhere. One of the reasons why the State of California has a permanent problem with drought is that it is home to the majority of the cloud computing facilities in the United States.

Research on mediatisation has so far failed to engage with the material foundations on which contemporary communications systems are constructed, focusing instead on the, albeit crucial, ways in which communication networks are being employed to intensify surveillance of the civilian population by collecting and collating every trace that individuals leave as they move across digital webs of connection.

\section{Big Data and Deep Capitalism}

In a recent call for contributions to a conference on data, Hepp and Couldry argue that the increasing interweaving of "what we call media and communication... with the process of datafication in an environment of continuous and largely automated data processing" presents a pressing challenge for "critical communications and social research-indeed for critical social theory and political action generally" (Couldry and Hepp 2017, 1). They see this development as "part of a process of "deep mediatization'-in which the very elements and building-blocks from which the social is constructed are based in processes of mediatisation, accompanied by automated data processing" $(2017,1)$.

In an earlier piece, however, Nick Couldry has acknowledged that "the intensification of connection and monitoring online" is being driven primarily by "deep economic processes" through which "The spaces of social life have become open to saturation by corporate actors, directed at the making of profit and/or the regulation of action" (Couldry 2016). In common with Joseph Turow, this argument restores "the centrality of corporate power" to "the very heart of the digital age" (Couldry 2016). It follows from this that we need to begin analysis with the dynamics of "deep capitalism" rather than "deep mediatization". 
The pursuit of profithas always involved efforts to monitor consumers in the interests of maximising sales. Tastes and preferences have been logged, choices and purchases tracked, and social groups identified as targets to be aimed at more intensively on the basis of their spending power. But these efforts generated mostly bulk data, summative characterisations of market segments. Monitoring Internet activity allows corporations to construct personalised profiles. Individuals are no longer subsumed in statistical tables or descriptive categories; they are identified, sorted and labelled on the basis of their online clicks, likes and social connections. The construction of these digital doubles or doppelgangers provides corporations with unprecedented opportunities to reach into the most intimate corners of everyday life and direct attention and action. It is this deepening of market fundamentalism's drive to reorder social life in the interests of capital that is shaping the processes that mediatisation research addresses. The harvesting of the same data streams by state security agencies adds a second moment of doubling, with individuals reclassified as either safe or potentially dangerous to social order.

The democratic revolution which formed the political cornerstone of western modernity promised an end to the exercise of arbitrary power. People were no longer to be subjects of kings or emperors, subjected to their unchallenged authority. They were to become citizens, free and equal members of a shared moral community, with the right to participate in determining the laws and rules under which they consented to be governed. The corporate capture of the Internet abandons this social contract. Firstly, by relentlessly addressing Internet users as consumers and conflating freedom with choices made in the marketplace, it continually undermines citizenship's insistence that self-realisation carries a commitment to contributing to the quality of the collective resources that provide essential material, social and cultural supports for personal agency. Secondly, in the absence of effective regulatory constraints, it has installed a highly asymmetric exchange designed to advance corporate rather than common interests and limit public debate on the exercise of economic power. Corporations know almost everything about our activities but we know almost nothing about theirs. Disclosure of their strategies and intentions is highly selective and carefully massaged by public relations. The bases of the algorithms directing user activity are protected by intellectual property regimes and commercial confidentiality. We do not have access to the digital information held on us or to the sorting systems that assign us to classificatory categories. They own our digital selves. This is the Faustian pact we have signed in return for access to expanded connectivity.

Moving corporate strategies to the centre of analysis inevitably raises questions of responsibility. In an earlier characterisation of this latest stage in the unfolding process through "which our social world becomes entangled with media" as "deep mediatization", Andreas Hepp offers an agent-centred account that constructs it as "a process promoted by specific groups of actors" $(2016,919)$. He is referring to the pioneer communities in the vanguard of developing new digital applications, mentioned earlier.

The critical political economy perspective that I have been advancing here insists on starting with the interests and actions of the corporate elite and their political supporters, and detailing the way media and communications in advanced capitalism have been reconstructed to address the continuing crisis of accumulation. This is not to claim that the processes which mediatisation theory, in both its institutional and actororiented variants, has placed on the research agenda are not important and deserving of sustained investigation. Clearly theyare. Butitis to argue that we need to begin our analysis by placing developments and innovations in media and communication systems firmly in 
the context of the overall shift in the organisation of advanced capitalism driven by market fundamentalist models of enterprise and growth. This dynamic has reconstructed the overall arena in which contests over the production and control of communication applications and uses are fought out and has rewritten the central rules governing the terms of engagement.

At the same time, it has generated new points of tension and contradiction and has opened new spaces of contest and struggle. As Nick Couldry (2016) notes, the "price" levied by deep capitalism operates "along dimensions that economists cannot count". These dimensions are expressly discounted by the ruling insistence in orthodox economics that the "economy" is a bounded domain with its own logics of operation which are best understood and evaluated through mathematical models that rigorously exclude ethical judgement. As I have argued elsewhere, returning to the tradition of political economy allows us to challenge both these assumptions; firstly by arguing that capitalism orders social and power relations as well as economic action, and secondly by insisting that political economies are always and everywhere also moral economies (Murdock 2011). Whenever we enter into any relation of exchange we are confronted with ethical choices around complicity in the social and environmental costs incurred in the production, deployment and eventual disposal of the goods and services we use. The ruling ideology of market fundamentalism has repeatedlyattempted to relegate the questions of justice, equity and solidarity raised by these entanglements to the bottom of agendas for public debate, but, as Nick Couldry (2016) has noted, we are "beginning to sense the ethical limits of capitalism's new game". Until now, however, mediatisation researchers have paid little sustained attention to alternative moral economies and their implications for the regulation, reform and reorganisation of contemporary media and communications.

The ascendency of commodification, commercialisation and consumerism is countered by moral economies of public goods and gifting. The corporate drive to enclose the digital domain is opposed by renewed conceptions of the commons as a shared cluster of rights and resources (Murdock 2013). Work on mediatisation has so far had little to say about these counter moral economies. Accounts of collective initiatives and struggles, and contests over alternatives, have mostly disappeared into the cracks between structural analyses of changing relations between established institutional domains and explorations of media in everyday life.

In a recent review of mediatisation theory, Nick Couldry has entertained the idea that "There are after all, alternatives to researching 'mediatization"” and that one "would be to turn one's research towards the wider transformations beyond media in which the media are somehow involved" (Couldry 2014, 33). I have argued here that a thorough understanding of the "wider transformations" in the organisation of capitalism is an essential prerequisite for contemporary critical analysis. This does not displace mediatisation research, but without a sustained investigation of the dynamics and contradictions of marketised capitalism it is impossible to fully account for the driving forces propelling and organising mediatisation, to properly grasp their consequences for institutional and intimate life or to identify possible routes to challenge and change.

Altheide, David L., and Robert P Snow. 1979. Media Logics. Beverly Hills, CA: Sage. Anderson, Chris.

2012. Makers: The Next Industrial Revolution. New York: Random House.

Bagdikian, Ben H. 2004. The New Media Monopoly. Boston: Beacon Press.

Birkinbine, Benjamin J., Rodrigo Gomez, and Janet Wasko, eds. 2017. Global Media Giants. London: Routledge.

Bucher, Tania. 2012. "Want to Be on the Top? Algorithmic Power and the Threat of Invisibility on

Facebook." New Media and Society 14 (7): 1164-1180. 
Couldry, Nick. 2008. "Mediatization or Mediation? Alternative Understandings of the Emergent Space of Digital Storytelling." New Media and Society 10 (3): 373-391.

Couldry, Nick. 2014. "Mediatization: What Is It?" In Media Practice and Everyday Agency in Europe, edited by Leif Kramp, Nico Carpentier, Andreas Hepp, Ilja Tomanic Trivundza, Hannu Nieminen, Risto Kunelius, Tobias Olsson, Ebba Sundin, and Richard Kilborn, 33-39. Bremen: Edition Lumiere.

Couldry, Nick. 2016. “The Price of Connection: 'Surveillance Capitalism'.” The Conversation, September 23rd. http://theconversation.com/the-price-of-connection-surveillance-capitalism64124.

Couldry, Nick, and Andreas Hepp. 2013. "Conceptualizing Mediatization: Contexts, Traditions, Arguments." Communication Theory 23: 191-202.

Couldry, Nick, and Andreas Hepp. 2017. "Call for Contributions to a Pre-Conference on 'Data and the Future of Critical Social Research' for the 2017 ICA Conference in San Diego." Accessed February 10, 2017. www.icahdq.org/mage/PC27.

The Economist. 2016. "Special Report-Companies: The Rise of the Superstars." September 17, $16 \mathrm{pp}$.

Fuchs, Christian. 2013. Social Media: A Critical Introduction. London: Sage.

Fuchs, Christian. 2014. Digital Labour and Karl Marx. London: Routledge.

Gamble, Andrew. 1994. The Free Economy and the Strong State: The Politics of Thatcherism. New York: New York University Press.

Gillespie, Tarleton, Pablo J Bockzkowski, and Kirsten A Foot, eds. 2014. Media Technologies: Essays on Communication, Materiality, and Society. Cambridge, MA: MIT Press, 1-17.

Hallin, Daniel C. 1992. “Sound Bite News: Television Coverage of Elections: 1968-1988." Journal of Communication $42(2): 5-24$.

Hepp, Andreas. 2016. "Pioneer Communities: Collective Actors in Deep Mediatisation." Media, Culture and Society 38 (6): 918-933.

Hepp, Andreas, Stig Hjarvard, and Knut Lundby. 2015. "Mediatization: Theorizing the Interplay between Media, Culture and Society." Media, Culture and Society 37 (2):314-324.

Hepp, Andreas, and Friedrich Krotz. 2014. "Mediatized Worlds: Understanding Everyday Mediatization." In Mediatized Worlds: Culture and Society in a Media Age, edited by Andreas Hep and Friedrich Krotz, 1-15. London: Palgrave.

Hjarvard, Stig. 2011. "The Mediatisation of Religion: Theorising Religion, Media and Social Change." Culture and Religion 12 (2): 119-135.

Hjarvard, Stig. 2013. The Mediatization of Culture and Society. New York: Routledge.

Ho, Karen. 2005. "Situating Global Capitalisms: A View from Wall Street Investment Banks." Cultural Anthropology 20 (1): 68-96.

Ho, Karen. 2009. Liquidated: An Ethnography of Wall Street. Durham, NC: Duke University Press. 
Jansson, André 2014. "Indispensable Things: On Mediatisation, Materiality, and Space." In Mediatization of Communication, edited by K. Lundby, 273-295. Berlin: De Gruyter.

Kristof, Nicholas. 2016. "Lessons from the Media's failure in its Year with Trump." New York Times, December 31st.

Krotz, Friedrich. 2007. “The Meta-Process of 'Mediatization' as a Conceptual Frame.” Global Media and Communication 3 (3): 256-260.

Krotz, Fredrich. 2009. "Mediatization: A Concept with Which to Grasp Media and Social Change." In Mediatization: Concept, Changes and Consequences, edited by Knut Lundby, 19-38. New York: Peter Lang.

Lievrouw, Leah A. 2014. "Materiality and Media in Communication and Technology Studies: Am Unfinished Project." In Media Technologies: Essays on Communication, Materiality, and Society, edited by Tarleton Gillespie, Pablo J Bockzkowski, and Kirsten A Foot, 21-51. Cambridge, MA: MIT Press.

Lunt, Peter, and Sonia Livingstone. 2016. “Is 'Mediatization' the New Paradigm for Our Field? A Commentary on Deacon and Stanyer $(2014,2015)$ and Hepp, Hjarvard and Lundby (2015)." Media, Culture and Society 30 (3): 462-470.

Maltby, Sarah. 2012. “The Mediatization of the Military." Media, War \& Conflict5(3):255-268.

Maxwell, Richard, and Toby Miller. 2012. Greening the Media. Oxford: Oxford University Press.

Mazzoleni, Gianpietro, and Winfried Shultz. 1999. “'Mediatization' of Politics: A Challenge for Democracy." Political Communication 16 (3): 247-261.

Moffitt, Benjamin, and Simon Tormey. 2014. "Rethinking Populism: Politics, Mediatisation and Political Style." Political Studies 62 (2): 381-397.

Murdock, Graham. 2011. "Political Economies as Moral Economies: Commodities, Gifts and Public Goods." In The Blackwell Handbook of the Political Economy of Communication, edited by Janet Wasko, Graham Murdock and Helena Sousa, 13-40. Oxford: Blackwell.

Murdock, Graham. 2013. "Communication in Common." The International Journal of Communication 7 (2013): 154-172.

Murdock, Graham. 2014. "Producing Consumerism: Commodities, Ideologies, Practices." In Critique, Social Media and the Information Society, edited by Christian Fuchs and Marisol Sandoval, 125-143. London: Routledge.

Murdock, Graham. 2015. "Financial Speculations: Contested Constructions of Markets and Crisis." In Money Talks: Media, Finance, Crisis, edited by Graham Murdockand Jostein Gripsrud, 125. Bristol: Intellect Books.

Murdock, Graham. 2017. “News Corporation.” In Global Media Giants, edited by Ben Birkinbine, Rodrigo Gomez Garcia, and Janet Wasko, 92-108. London: Routledge.

Qiu, Jack Linchuan. 2014. "Goodbye iSlave: Foxconn, Digital Capitalism, and Networked Labour Resistance." Society: Chinese Journal of Sociology/Shehui 34 (4): 119-137.

Schlesinger, Philip, Graham Murdock, and Philip Elliott. 1983. Televising 'Terrorism': Political Violence in Popular Culture. London: Comedia Publishing Group.

Schulz, Winfried. 2004. "Reconstructing Mediatization as an Analytical Concept." European Journal of Communication 19 (1): 87-101.

Streeck, Wolfgang. 2016. How Will Capitalism End? Essays on a Failing System. London: Verso.

Strömbäck, Jesper. 2008. "Four Phases of Mediatization: An Analysis of the Mediatization of Politics." The International Journal of Press/Politics 13(3): 228-246.

Strömbäck, Jesper, and Peter Van Aelst. 2013. "Why Political Parties Adapt to the Media: Exploring the Fourth Dimension of Mediatization." The International Communication Gazette 75 (4): 341-358. 
Waisbord, Silvio. 2013. “A Metatheory of Meditization and Globalization?” Journal of Multicultural Discourses 8 (3): 182-189. 